\title{
Challenges of doing research in sub-Saharan African universities: digital scholarship opportunities
}

\author{
Stephen Mutula' \\ Department of Library and Information Studies, University of Botswana \\ mutulasm@mopipi.ub.bw
}

\begin{abstract}
Universities the world over are responsible for research, knowledge generation, scholarship and innovation. They also serve as conduits for the transfer, adaptation, and dissemination of knowledge generated across the world. Universities are expected to guarantee the most efficient utilisation of research results and their possible application to economic life. Globally, universities are facing renewed external and internal pressure as the push for them to meet the changing needs of society intensifies as a result of trends in the transition towards a knowledge-based economy; massification of higher education; and the integration and assimilation of Information Technology (IT) into the academic environment. Moreover, the emergence and use of IT in higher education has led to an increasingly virtual education system, with implications for the dynamics and conduct of university research. Universities no longer remain sole citadels of research activities, as private or government research institutes are increasingly involved in knowledge creation and dissemination. The internationalisation of higher education, coupled with growing student mobility and increased competition for funding, has recently occasioned efforts to rank universities in terms of their academic quality and productivity at national, regional and global levels.

Despite the increased demands on universities, they remain constrained by declining state funding, increasing enrolments, limited physical facilities, etc. New technologies now offer lifelines for African universities to re-engineer and reposition themselves in order to meet these ever increasing societal demands effectively. This paper discusses the challenges of doing research in African universities, and assesses the opportunities digital scholarship can engender for these universities. The focus of the paper is on universities in sub-Saharan Africa, excluding North Africa and to some extent, South Africa. North African higher education is largely influenced by practices in Europe and the Middle East. South Africa has had a separate and distinct political history and governance that differs from other African countries. The country also has a fairly well developed technological and industrial economy, which is quite ahead of other African countries. Their system of higher education is older (most universities were established during the pre-World War II phase, while in most sub-Saharan countries, universities were established post-independence, beginning in the late 1950s) and their universities are well endowed with good libraries, well equipped laboratories, long traditions of scholarship based on European models, and a well established ICT infrastructure that is accessible to both faculties and students.
\end{abstract}

Keywords: Research, digital scholarship, e-research, e-learning, sub-Saharan Africa, higher education

\section{Introduction}

Recent university rankings generally show that African universities - save for some South African universities - are performing poorly. Other than research, ranking takes into account the teacher-student ratio, proportion of international faculty members in relation to local staff, and the number of international students (The Standard, 2006). Other criteria used include universities' research outputs and general contribution to new knowledge; levels of training and application of science and technology; presence on the Internet and use of Information and Communication Technologies (ICTs); volume of published material on the web; visibility and impact of the universities' web pages as measured by the citations (site visits) or links they receive (inlinks); perceived quality; institutional statistics; websites and surveys of students, scholars or employers to make comparisons between institutions; the number of Nobel and Fields Medal winners; articles published in Nature and Science; articles in citation indexes; and academic performance with respect to the size of an institution.

There is a significant amount of debate and controversy surrounding university rankings, especially with regard to the criteria used. Some universities feel that the methodologies used are flawed because the assessors do not visit the universities. Moreover, not all information can be found on websites, or the information used is outdated (e.g. the qualifications of faculty members obtained from the Association of Commonwealth Universities). Linking employment to the relevance of courses is also wrong, because the job opportunities available in any given economy influence the employment rates and may not directly relate to the quality of graduates. Additionally, universities in different regions face different challenges, and this in itself suggests that different criteria should be used. For example, across many institutions the number of students and the number of faculty staff or postgraduate programmes differ (Siringi, 2005). Nevertheless, university rankings are used by students and others to inform them in their decisions about universities, while at the same

I. Stephen Mutula, PhD, is an Associate Professor and Head of the Department of Library and Information Studies, University of Botswana, Botswana 
time providing them with an indication of the quality of graduates. In some countries, rankings are used to determine the proportion of funding given to universities. Rankings also summarise the global performance of any university, and reflect the commitment to the dissemination of scientific knowledge. Rankings may be used as proxies for employment opportunities as they have the potential to serve as screening devices for employers, and may also function as indicators of research quality. Employers compete strongly for the acquisition of postgraduate students from reputable academic institutions, and even offer positions well in advance of these students' completion of academic programmes. According to the authors, evaluation has had a significant impact on the performance of universities worldwide. For example, evaluation has prompted researchers to increase their publication output in visible journals. Ranking has also increased awareness among academics on how best to make their research activities public (The Standard, 2006).

World university rankings are dominated by institutions in wealthy countries, particularly those situated in Europe and the United States. However, some South African universities perform relatively well and dominate in Africa. Four of South Africa's 23 universities, or 17\% of the country's institutions, were placed in the top 500 globally by the 2006 Academic Ranking of World Universities. These institutions were the University of Cape Town (at 252), University of the Witwatersrand (396), University of KwaZulu-Natal (470), and the University of Pretoria (48I). The only other ranked African institution was the University of Cairo in Egypt, which was placed at 402 out of 500.

Academic Ranking of World Universities - Africa Rankings

\begin{tabular}{|l|l|l|}
\hline Rank & Country & University \\
\hline 252 & South Africa & University of Cape Town \\
\hline 396 & South Africa & University of the Witwatersrand \\
\hline 402 & Egypt & University of Cairo \\
\hline 470 & South Africa & University of KwaZulu-Natal \\
\hline 481 & South Africa & University of Pretoria \\
\hline
\end{tabular}

(Source: Institute of Higher Education, 2006).

According to 2008's global ranking of world universities, produced by the Institute of Higher Education at Shanghai Jaio Tong University in China, only three African universities remain in the top 500. The Universities of Cape Town, Witwatersrand and KwaZulu-Natal are in the top 500; however, two other universities have fallen off this list. A similar ranking by the Spanish-based Internet Lab Ranking of 30 top African universities places UCT (398); Stellenbosch (566); UP (7I8); Wits (720); Rhodes (738); UNISA (I449);... UZ (3724) (InternetLab, 2008)

Although African universities have been known to suffer from various constraints that affect the quality of research and learning, the ranking of universities has ruffled some egos, especially because of the impact such ranking could have on resource allocation and attracting students and staff in a globalised competitive environment. The National Universities Commission (2006) in Nigeria points out that universities in that country do not have web presence and perform poorly in webometric ranking - factors that can make them lose their esteem in the eyes of stakeholders, such as potential students and funding agencies. This in turn may affect academic exchange with reputable universities from other parts of the world for teaching and research. The National Universities Commission pointed out that Nigerian universities were performing poorly with regard to research in a digital dispensation because of the scant attention paid to presenting research findings in web-searchable forms; low impact local journals without Internet links; lack of publication in electronic journals; and the absence of Nigerian universities on the Internet (i.e. no web addresses). Most indicators used in the rankings of universities rely, to a great extent, on applications and the use of ICT. However, the International Education Association of South Africa (2008) points out that [whereas] ICT should underpin technology, innovation, research, communication and the development of the knowledge economy. In most SADC states, ICT resources are poor or virtually non-existent in sub-Saharan universities, with $80 \%$ of the region's universities inadequately connected.

Sawyer (2004) observes that research capacity development in most African countries represents an instance of market failure because explicit public policy does not exist to reinforce and ensure that higher education and research receive adequate investment from both private and public sectors for infrastructure development in the form of laboratories, equipment, libraries, and a system of information storage, retrieval, and utilisation. The poor performance of African universities in international rankings, especially with regard to research, is exacerbated by the fact that some universities do not offer $\mathrm{PhD}$ programmes. For those that do offer $\mathrm{PhD}$ programmes, the rates of student completion are too low to compete globally, let alone meet the national needs of government, private sectors and universities. This is exacerbated by the fact that it takes on average 6-8 years to complete a PhD as a result of inadequate resources and 
bureaucracy in the approval process involving departments, faculties and universities (Szanton and Manyika, 200I). Due to limited staff capacity, most PhDs are based on dissertations alone, and do not include course work, comprehensive exams, and multi-disciplinary supervisory committees. Szanton and Manyika (200I) provided some statistics on the number of PhDs produced in African countries as follows: the University of Ghana, in Legon, awarded I5 PhDs between 1998-200 I in all disciplines; Makerere University granted 43 PhDs between 1990-1998 in all the sciences; the University of Dar es Salaam issued 56 PhDs in all fields between 1990-1999; the University of Zimbabwe granted 32 PhDs in agriculture, arts and social sciences in 200 I; UCT produced 382 PhDs between 1996-2000; and the University of Pretoria produced II00 PhDs between 199I-2000.

Challenges attributed to scholarly research in most African universities also include the descriptive nature of research and the lack of empirical rigour (in part due to a lack of resources); paucity of cross-disciplinary research endeavours; limited collaborations between practitioners and academics; limited linkage between research and the national development agenda (Moahi, 2007); decreasing state subsidies (Botha and Simelane, 2007); shortage of research expertise and experienced supervisors (Biermann and Jordaan, 2007); high subscription costs of scholarly journals; limited publishing infrastructure; lack of incentives for researchers; inadequate mentoring frameworks; and weak or non-existent partnerships (Lor, 1998). Moreover, research done in African universities tends to focus on local or national development issues by putting an emphasis on applied research at the expense of basic research. The focus on national or regional issues may mean that research outcomes are generally not widely applicable to international issues. This is exacerbated by inadequately equipped libraries, with limited access to modern journals and the Internet. Szanton and Manyika (200I) note that because African university libraries have suffered huge financial losses, neither doctoral students nor their local faculty supervisors are likely to have access to current theoretical and comparative literature that might provide new and valuable insights in their dissertation projects. In most libraries, books are ancient, unavailable or the pages largely mutilated. University presses are under-funded or non-existent, and university journals are either few or unavailable. Due to inadequate experience and the lack of contacts, junior members of staff find it difficult to publish in international journals. Consequently, dissertations end up being stacked in libraries, leading to inbreeding.

\section{0-1980s: Post-independence challenges of African universities}

African countries began attaining their independence in the 1950s, and made fighting poverty, illiteracy and disease their major preoccupation in order to improve the lives of their people, who had been downtrodden and marginalised from mainstream or national economic activities under colonial governments. Soon after independence, there was heavy investment in education (especially the training of graduate and technical personnel) in order to develop adequate manpower to take up newly available positions, especially in the civil service.

Mamdani (2006) observes that the post-independence era of the 1960s and 1970s in African universities experienced a boom when many governments pumped investment into new and existing universities. For instance, in Nigeria the preindependence era had one university with I,000 students in 196I; 30 years later it had 4I universities with I3I,000 students. Most African universities generally succeeded in providing high level personnel to the civil service, schools and to the applied sciences - medicine, agriculture and the social sciences (Halsey, 1992; Slaughter, 1998). The initial enthusiasm for higher education by governments after independence was short-lived, as this was followed by a sharp decline in the number and quality of universities, attributed to factors such as falling commodity prices, a sharp rise in the price of crude oil, trade barriers, declining GDPs, political instability, and debt crises. Sutherland-Addy (I993) observed that by the 1980s universities were in a state of crisis. The decay of physical facilities, with much of the facilities in need of maintenance and refurbishment, and the lack of modern electronic and technological infrastructure and poorly stocked and managed libraries were widespread features of African higher education. Ahemba (2006) notes that 'in Nigeria, The Ivory Coast, Kenya and Uganda, crumbling faculties and campuses, overcrowded lecture halls and hostels and depleted libraries and laboratories bear sad witness to (former and still prevalent) chronic shortages of funding and investment'. The situation was further exacerbated by poor governance, characterised by a lack of democracy, single party states, coups, detentions without trial and political assassinations.

These negative developments for universities were happening against the backdrop of the universal 'massification of universities', where according to the World Bank (2000), student numbers in African universities rose from 350,000 in 1975 to $1.7 \mathrm{~m}$ in 1995. At the same time, most African countries faced the challenges of rapidly growing populations and declining economic growth, a slow degree of industrialisation, unemployment, disparity in the distribution of income, escalating costs, declining academic achievements, etc. The economic difficulties forced the countries to turn to the World Bank and IMF for donor support. In return, the World Bank and IMF demanded that these countries undertake Structural Adjustment Programmes (SAPs), which included significantly reducing government expenditure on social services. In addition to the SAPs, the World Bank argued that economic and social returns on primary and secondary

Inkanyiso, Jnl Hum \& Soc Sci 2009, I(I) 
education were higher than on tertiary education (Psacharopolous, 1980). Universities consequently suffered reduced government funding in line with these demands. Kenya, for example, decreased its national recurrent budget on education from 38\% in 1987/88 to 19\% in 1988/89 (Maina, 1989:1 10). A further decrease followed in 1992/93 to 18\% (Republic of Kenya, 1993:88). This was accompanied by government reducing per student expenditure from an average of US\$6,300 in 1980 to approximately US\$ I,200 in 1995.

As a result of these declining fortunes, Szanton and Manyika (200I) state that African universities had to endure a period of approximately 15-20 years during which salaries remained flat or were lowered; research funding dried up; faculties could not maintain membership in professional associations or attend international conferences; libraries stopped purchasing books and journals; physical facilities (classrooms, hostels, labs, etc.) crumbled; the building of new structures was terminated; scholarships for faculties were either declined or stopped; pensions for staff became uncertain; and the hiring of new staff stopped while the brain drain increased. In addition, medical cover that faculties had enjoyed were eliminated, as were subsidised housing, car loans, etc. When the situation within universities became unbearable, student and faculty activism against government emerged on campuses. Feeling threatened, governments started to clamp down heavily on universities, leading to an exodus or exile of faculty staff members and students to foreign countries, especially to Europe and North America, while others were detained without trial in places like Kenya and Nigeria. Faculties that endured and remained were lured locally into consultancies to undertake applied research on behalf of donor communities, without being replenished by the universities from which they came. Blair and Jordan (1994) claim that the massive brain drain of well trained and skilled academic staff, mainly to Europe and North America, was estimated by the World Bank at 23000 qualified academic staff leaving every year.

Figures vary, but currently it is estimated that there are more than 300,000 highly skilled and experienced professionals from Africa living and working in Europe and North America (of these, more than 40,000 are PhD holders), comprising doctors, lecturers, researchers, nurses and professional managers (Kenya Times, 2006 quoting deliberations at the UNESCO Conference I4 February 2006). In Kenya alone, the World Bank reports that nearly $40 \%$ of the country's highly skilled professionals emigrate to rich countries. The rate of emigration in Kenya's case is about double that of Africa as a whole, with about $20 \%$ of its skilled workers having moved from Africa to the developed world. The migration of the highly skilled cadre of academic professionals and students has led to an acute shortage of academics in Africa's higher education institutions, especially in key fields such as science and engineering (Oketch, 2000). President Kibaki of Kenya lamented that the country was losing Ksh 20 billion (ZAR 2 billion Rand) annually in capital flight paid by students in fees abroad because of the country's incapacity to absorb all those seeking higher education locally (Siringi and Kago, 2006).

\section{Prospects for universities in Africa}

By the turn of the new millennium in 2000, there was a wind of change following the collapse of the Berlin Wall, which was followed by the increased democratisation of Africa as pressure from the international community mounted and donor funding became tied to good governance. That aside, there was also an emerging crop of new leaders in Africa with democratic credentials, such as Yoweri Museveni of Uganda, Frederick Chiluba of Zambia, Meles Zenawi of Ethiopia, Joachim Chissano of Mozambique, John Kuffor of Ghana, etc. The unbanning of the ANC and the release of South African freedom icon Nelson Mandela renewed the hope of many in African countries and their universities.

The post 1990s period has seen a unified international approach to alleviating global poverty (Millennium Development Goals) by increasing the use of ICT to enhance good governance (e-government), enhancing economic development (e-business and e-commerce), bridging the digital divide (WSIS), and increasing access to education (elearning, etc), thus putting universities back in the limelight. The World Bank (200I) now acknowledges that in order for countries to deal with the challenges of the new millennium such as globalisation, reducing poverty, working within the knowledge based society and bridging the digital divide, there is a need for a highly skilled workforce, a role universities are well placed to play. The World Bank (1993) noted that any country aspiring to lay a strong foundation in socioeconomic development must put the responsibility on higher education institutions to equip individuals with the advanced knowledge and skills required for positions of responsibility in government, business and the professions. Universities are perceived as important entities in helping government develop policies and strategies to meet MDGs targets, and produce much needed skills for industrialisation in the knowledge economy.

The African Association of Universities (AAU) and South African Vice-Chancellors, realising the strategic importance of universities in the new millennium, started a campaign for the revival of universities by petitioning government through the African Union and NEPAD to try to address the malaise afflicting universities on the continent. The campaign was given impetus by the increased democratisation of the continent, and the wind of economic reform as characterised by economic liberalisation, pluralist-political reforms, the emergence of multi-party democracies and the clamour for good governance by both the governed and international development agencies. Responding to the request by the AAU at the 
I Ith conference in 2005, held in Cape Town, President Thabo Mbeki called on universities to raise their voices and actively assist development and respond to the unprecedented support from developed countries (MacGregor, 2005). The president outlined three major challenges faced by universities, i.e. the need to analyse problems and offer practical solutions; the need to set up centres to measure progress in key areas such as democracy, peace, stability, human rights and development; and the need to support socio-economic development on a continent that "now speaks with one voice" about Africa's pressing needs. Similarly, the Commission for Africa's (2005) report argued that stronger universities could help improve the accountability of governments and build participation and citizenship, and generate independent research and analysis that supports vibrant debate. This in turn can greatly improve the effectiveness of government policy and other services. Universities are also critical to tackling a chronic skills shortage on a continent that loses many, if not most, of its scholars through the brain drain.

Increasingly, most universities have now also awakened to the fallacy of solely depending on government for full financial support. Following reduced donor funding, governments in Kenya, Zambia, Uganda, Tanzania, Malawi, etc. started to take extraordinary measures to survive. For example in Kenya, the Higher Education Loans Board was established to facilitate the financing of university education to more deserving Kenyans and improve the recovery of loans that had been advanced to beneficiaries of university education who were now in employment. At that point in time, only $20-25 \%$ of loan recipients ever paid back their loans because of poor tracking systems and follow-ups on the part of government (Woodhall, 1991:55).

Moreover, governments have started to encourage the private sector to participate in the provision of higher education. In Kenya and Zambia, tuition fees were introduced during the late 1980s, and universities were required to adopt corporate models so that they could become self-financing. Kenyan universities introduced parallel degree programmes for those in working positions who met university entry requirements and fresh students from high school who did not secure entry into universities because of the competitive selection process. Those who now gain entry to parallel degree programmes pay fees at global market rates. Saint (1992) reported that the University of Zambia and Eduardo Mondlane University in Mozambique established internet nodes linked to local electronic networks that sell subscriptions to non-university affiliated businesses, organisations and individuals. The University of Ghana was reported to be making a profit of $9 \%$ on a total income of US $\$ 22700$ in 1991 through its consulting centre. Similarly, Nsukka University claimed a profit of US \$35,238 through its consulting activities over the period 1982-1991, on a turnover of US $\$ 90398$, with the consultants receiving $50 \%$ of the profits, and the university and departments receiving $30 \%$ and $20 \%$ respectively.

Most universities in Africa are now thinking strategically by developing strategic plans and mission statements that aspire to offer practical experiences to encourage innovativeness; introducing performance management systems to enhance the quality of education; and seeking partnerships with industry, government, NGOs and communities. Although the challenges of the new millennium have seen universities begin to regain their former glory, they are coming under renewed pressure of a different kind. Szanton and Manyika (200I) outline these pressures as the need to: produce highly skilled graduates who can globally compete in the knowledge economy; relate curriculum to labour demand; reconstruct the curriculum to meet African needs; increase equity of under-represented populations; support critical, basic research, theory building, experimentation and teaching; deal with HIV/AIDs; lead in social transformation rather than act as conservative or elitist institutions; forge links with industry and government in order to become more innovative and relevant to society; and participate in or form part of government policy making organs.

\section{Digital scholarship opportunities for African universities}

African universities have, for the last five years (since 2004) in a row, been ranked behind their counterparts in the global league of universities with regard to frontiers of knowledge and research. Some of the indicators used in evaluating universities are ICT-based, such as visibility, web links (in-links and outlinks), statistics maintained, webometric citations, etc. Szanton and Manyika (200I) noted that in African universities there is little emphasis on the careful collection and consolidation of information, and they attribute this to the inadequate deployment of ICTs in the learning and research environment of the universities. Moreover, given the resource constraints universities face, the record keeping of research (degrees, disciplines, completion rates and topics of research) has not been prioritised. Most research is still kept offline. Onyancha (2008) found that Africa only represents 1\% (13) of global repositories, with the leaders being Europe 48\% (52I), North America 38\% (328), Asia 8\% (106), Australasia 6\% (66), South America 4\% (4I), the Caribbean $0 \%(\mathrm{I})$ and Central America $0 \%$ (I). South Africa dominates in Africa with 10 institutional repositories, followed by the remaining three in Uganda (I), Zimbabwe (I) and Namibia (I). The South African institutional repositories include: AHERO (African Higher Education Research Online); CSIR Research Space; Durban University of Technology IR; Electronic Thesis and Dissertation Database of the University of Johannesburg; University of Pretoria's

Inkanyiso, Jnl Hum \& Soc Sci 2009, I(I) 
Institutional Research Repository; Rhodes eResearch Repository; Stellenbosch University Institutional Repository; UCT Computer Science Research Document Archive; University of Pretoria Electronic Theses and Dissertations; and University of Western Cape Theses and Dissertations.

Tarpeh (1994), in a report for the African Association of Universities based on studies in universities in Cote d'Ivoir, Ghana, Nigeria and Zambia, emphasised the need for strengthening the statistical database of the universities. Although libraries are expected to maintain lists and also keep theses and dissertations, this information is not easily available to the university community as a whole because digital technologies have not been applied. Moreover, limited internet connectivity, low bandwidth, limited access to computers and limited support still remain challenges. The World Bank's 1998/99 World Development Report called for radical changes - such as the infusion of ICTs in post-secondary education - if Africa was to equip its labour force with the skills needed to survive in the new technological age.

African universities that choose to ignore the deployment of ICT in learning and research do so at their own peril. The academic environment in universities the world over is undergoing tremendous transformation. The teaching and research work of academic institutions, historically based on the printed page as expressed through libraries and their physical collections of books, journals and documents have been at the heart of universities. However, academic work is being transformed as the shift takes place from print media, such as books, to the internet and digital media. In addition, a different kind of student is also emerging, with greater computer literacy and a different approach to information seeking, mainly through Google (Youngman, 2007). In sum, digital scholarship is now emerging in universities. Many definitions of 'digital scholarship' abound, but Prof. Kirsten Foot from the University of Washington's Department of Communication sums it up coherently 'as any element of knowledge or art that is created, produced, analysed, distributed, published, and/or displayed in a digital medium, for the purpose of research or teaching'.

Digital scholarship may also be perceived as a 'networked, scholarly or academic environment with pervasive integration of digital technologies in everyday learning and research, the necessary physical infrastructure both on and outside campus for access, integration of university information systems such as institutional repositories, online public access catalogues and content management systems, that allow seamless access to content needed for research, publication and scholarly communication'. From these definitions, it is clear that digital scholarship is broad-based and may include one or more of the following: submission of articles, peer review and publication, all done electronically; teaching using pure or blended electronic means; evaluation and assessment of academic work electronically; electronic collaborative research; and electronic communications, e-journals, e-books, and a variety of databases and digital libraries.

The other concept closely related to digital scholarship is e-research, which, according to O'Brien (2005), refers to large-scale, distributed, national or global collaboration in research that typically entails harnessing the capacity of information and communication technology (ICT) systems, particularly the power of high-capacity distributed computing, and the vast distributed storage capacity fuelled by the reducing cost of memory, to study complex problems across the research landscape. E-research is quite beneficial in university environments. It provides researchers with opportunities to develop whole new areas of valuable research and to view existing research in new ways. Through cyber infrastructure, it is possible to link expensive equipment and provide data mining and curation, thus enabling scholars to work in large global research teams on large amounts of data. By making this form of data accessible, some of the stored data may be used up several times for different aspects of research. Access to common data can allow parallel research projects to take place simultaneously. Digital scholarship offers the opportunity to develop cyber infrastructure that is critical for collaborative research and the sharing of resources. Through e-research and collaboration, it is possible to gain access and archive global, rare field-recordings that are at risk of being lost. The archived data can also be enhanced by subsequent students' projects, where metadata is added and stored in a digitally sustainable format, further building this rich research resource. Such records can be made accessible to researchers internationally, allowing new research to occur.

Among the many transformations taking place in universities is the increasing tendency to deliver information online, with libraries responding by making attempts to digitise material that was once only in print format. This action is necessary because it enables collections to be delivered to users $24 / 7$ via intranets, the Internet and other fast and emerging networks. Similarly, digital information resources are increasingly being relied on as primary or complementary information sources of scholarship. Scientific journals that were, a few years ago, produced largely in print format, are now rolled out first as e-versions. Libraries are also transforming their print collections through digitisation or subscription to e-journals, with or without print alternatives, as a strategy to make them more accessible and to enhance resource sharing.

The potential for digital scholarship is enhanced by the increased sophistication of search engines and global library digitisation projects, such as the one that was undertaken by Google in 2004. Moreover, the net generation students also 
enhance digital scholarship because they are digitally literate and largely dependent on Google or other search engines for discovery of information resources rather than consultation of library web pages, catalogues and databases as the main sources of information (Lippincott, 2005). Besides, the possibilities offered by Web 2.0 for modern libraries expand the opportunities for implementing digital scholarship projects. Web 2.0 refers to second generation, internet-based services, such as social networking sites, wikis, communication tools and folkosonomies that emphasise online collaboration and sharing among users (O'Really, 2005). Web 2.0 provides new possibilities for creating metadata, virtual references, information literacy, digitisation, and creating digital repositories.

Through Web 2.0, it is possible to develop e-research opportunities. E-research is defined as a collection of distributed computing resources (data repositories, specialised scientific equipment, computing power, knowledge services etc.) that appear to users as one virtual system (OBrien, 2005). The concept of Library 2.0 has emerged to refer to libraries that integrate all e-resources into a single point of access with a uniform interface, OPAC (consisting of federated search engines), RSS (used for cataloguing and searching results), a 'physical' library that is a loud space for collaboration and conversation through the use of mobile devices, and the integration of the library with e-learning. Likewise, the Patron 2.0 concept enabled by Web 2.0 is making it possible for patrons to not only be content consumers, but creators as well (Pienaar, 2008).

In order for digital scholarship to be institutionalised, a number of interventions are required, such as: an e-strategy; a research portal that would facilitate data transfer; knowledge sharing, including protocols of uploading; open access standards; institutional repositories; digital scholarship/e-research librarians responsible for training, re-orientation and liaison; digital curation services, including standards, software, marketing and training; and portable access/cyber infrastructure (Pienaar, 2008). The e-research strategy would help focus the organisation, keep the organisation on the cutting edge of new developments, provide a framework for capacity building, define operational standards, integrate einformation applications in the organisation, cater for adequate cyber infrastructure, define information products and services, enable the creation of digital repositories, define procedures for digital archiving, define the mandate for digital scholarship, explain sustainability issues, provide quality assurance, and define open access procedures, to name a few. Pienaar (2008), citing the context of the University of Pretoria, maps out the e-environment for scholarship as: eresearch, e-learning, e-resources, open scholarship, digitisation, Web 2.0/Library 2.0, institutional repositories, and Library Web.

According to Pienaar (2008), the e-research component is responsible for:

- Digital data curation (data acquisition, creating meta data, annotation, provenance, data storage, data cleansing, data mining, curation and preservation)

- Liaisons with other institutions

- Developing the virtual research environment, and

- Establishing digital scholarship advocacy.

E-learning would be responsible for developing e-skills, the seamless integration of library information, and carrying out information literacy. Digitisation would be responsible for developing digital preservation strategies, equipment requirements, and providing space for digitisation, while open scholarship would be responsible for developing strategies for open scholarship and integrating accredited journals with journals that support open access. Repositories would develop strategies for digital repositories and integrate various e-resources. Library web is basically the portal and gateway to the information in the repository. Web 2.0/Library 2.0 would develop strategies that enhance the user environment i.e. content creation, learning spaces, etc. E-resources would deal with acquisition, the organisation of eresources, and transforming resources into interactive interfaces. For effective operationalisation, each of these components may be assigned a group of specialists in the area, or a committee.

O'Brien (2005) proposes the following requirements for e-research:

Technical infrastructure and services - ICT infrastructure (high performance computing), networks, data management and storage, repository management, grids, digitisation, data mining, statistical support, data preservation, authorisation and authentication mechanisms, and help desks.

Leadership and coordination - brokering the needs of academics by providing connections to necessary support structures or expertise on campus; providing a management structure for e-research across the university; and collaborating with other relevant bodies on campus to foster knowledge and resource sharing across campus communities.

Buchhorn (2004) posits that researchers' e-research requirements include: 
- Access to storage and computational resources

- Access to computational software and services

- Videoconferencing and collaboration tools

- User-friendly, application-specific, web-based portals

- Shared access to large data repositories for searching, replication and updating

- Assistance with organising and managing research data sets

- Collaborative steering of remote research experiments and the ability to collaborate in international projects

Digital repositories form one of the most important components of the digital scholarship environment. A digital repository enables easy access to scholarly literature and provides the quickest means of accessing and also disseminating research output. It increases the visibility of authors, making their works widely read. Pienaar and van Deventer (2007) observe that institutional repositories enhance researcher efficiency; integrate systems (across the entire research cycle) and cut out personal duplication; facilitate the utilisation of colleagues' results, which cuts out duplication across organisational boundaries; enable real time communication of research results; and help students and staff easily identify research areas. Repositories can vary in scope, and may be departmental, institution-wide, individual, disciplinary or governmental repositories. Institutional repositories can enable access to documents such as theses and dissertations that are often not disseminated widely. Technical reports can also be archived, including standards, best practices, etc. Such repositories can help prevent the duplication of research work, facilitate access to local content, enable the publication of local content, and make contributions to global scholarly knowledge. A list of institutional repositories can be found through search IR directories such as Directory of Open Access Repositories (DOAR) and Register of Open Access Repositories (ROAR) (Onyancha, 2008).

The digital scholarship environment can facilitate access to a wide range of literature in electronic databases, digital libraries and the institutional repositories of other universities, and consequently help address the dearth of information resources that universities in Africa are faced with. Through digital scholarship, it is possible for universities to enhance quality research; make contributions to global knowledge; enhance content development; help bridge the digital divide; provide access for greater numbers of students to higher education; and make access to higher education more democratic and liberalised.

Kraut et al. (2003) note that the Internet has changed communication and is enabling researchers to observe new or rare phenomena online and conduct research more efficiently, enabling them to expand the scale and scope of their research. The Internet has also enabled scientists to collaborate by increasing the ease with which they can work with geographically distant partners or share information (Walsh \& Maloney, 2002). Research enabled through the Internet lowers many of the costs associated with collecting data, especially with regard to human behaviour, as ICT enables the hosting of online experiments and surveys, allows observers to watch online behaviour, and offers the mining of archival data sources. Through online research, data can be collected from thousands of participants with minimal intervention on the part of experimenters, for example through Internet chat rooms and bulletin boards, which provide a rich sample of human behaviour for studies on communication (Nosek, Banaji, \& Greenwald, 2002).

\section{Challenges of digital scholarship}

Despite the potential ICT offers in research, there are several challenges facing researchers in a digital environment, especially within the context of the developing world (in this instance, in Africa). Mutula et al. (2006), in an empirical study of e-learning at the University of Botswana, identified the following problems facing students:

- A shortage of computers

- Lack of clarity of online content

- Poor Internet connectivity

- Difficulty in finding information on the Internet

- An inability to cope with the workload

- Poor formats of presenting online content

- The lack of appeal of online content, etc.

When asked how well the materials were presented online, some felt that the presentation was inadequate. As to whether the online course was designed with their needs in mind, 58 (67.4\%) of the 86 respondents said yes, 17 (19.8\%) said no and II (12.8\%) did not know. Gerhan and Mutula (2005), in a study on the bandwidth problems at the University of Botswana, similarly found that a shortage of computers is often cited as a major setback hampering effective e-learning. In addition, students often complain of poor Internet connectivity. 
Digital dispensation places a heavy demand on library and information professionals. Stueart (2006) notes that information facilitators in the information age are being called upon to help people use resources; enhance outreach services to various users, such as faculties; and work with users at the desktop to show them how to use databases. The librarian is also being seen as an information consultant involved in behind-the-scenes activities, such as helping software designers develop systems that fit users' information seeking behaviour. They are also increasingly getting involved in developing and imparting information literacy while also acting as negotiators responsible for identifying needs; facilitators for providing effective search strategies; educators familiar with literature and information in many formats; and information intermediaries responsible for providing current awareness services and liaisons between the information seeker and the information itself. The librarian is now also perceived as a knowledge manager responsible for supporting the knowledge access process by directing users to other knowledge experts.

Doing research in the digital era is made difficult because there is currently no sampling frame that provides an approximate random sample of Internet users. Unlike what can be achieved by randomly dialling telephone numbers, which provide an approximate sample of countries' populations, the problem associated with achieving a reasonable level of 'representativeness' is exacerbated by the fact that online surveys and experiments rely on opportunity samples of volunteers. As a result, it is not clear how one should go about the task of appropriate generalisation (Kraut et al., 2003). Moreover, Internet-based surveys pose challenges of generalisation because response rates to online surveys are typically lower than comparable mail or telephone surveys and, when given the choice of Internet or paper questionnaires, respondents still overwhelmingly choose paper (Couper, 200I). The researcher also does not have control over the environment in which the research is conducted, especially when compared to other experimental settings, given that when people are not identified, they feel less accountable for their actions (Sproull \& Kiesler, 199I). The basic ethical principles underlying research involving human subjects, namely respect for persons, beneficence and justice; are difficult to uphold in Internet-based research. This is because, as pointed out by Kraut et al. (2003), Internet research involves two potential sources of risk: harm resulting from direct participation in the research (e.g. acute emotional reactions to certain questions or experimental manipulations), and harm resulting from breach of confidentiality.

Hedstrom (2002) outlines some of the research challenges in a digital dispensation. In particular, digital collections are vast, heterogeneous, and growing at a rate that outpaces our ability to manage and preserve them. There are no effective and cost-effective methods to preserve dynamic databases, complex websites, analytical tools or software for long-term retrieval. In addition, digital resources are impossible to interpret or use without accompanying tools for analysis and presentation. Besides, digital content can also not withstand some unspecified period of neglect without this resulting in total loss. There are questions of intellectual property rights, privacy and trust which must be addressed by researchers. Access to digital content sometimes experiences interoperability problems, especially across widely distributed and heterogeneous digital archives.

Most of the content providers of digital material are in the developed world, and they are increasingly moving away from the purchasing model to licensing, which often overrides conventional exceptions to copyright as contained in national legislations, such as fair use and fair dealing. This makes it difficult for the information provider to freely avail such information for academic use without breaching agreements of license, further alienating developing countries from mainstream information (Kiggundu, 2007). In addition, the high costs of access to external databases and for the procurement of digital information makes it increasingly difficult for libraries in the developing world to subscribe to new journals and books, or even maintain existing subscriptions.

\section{Way forward and conclusion}

O'Brien (2005) notes that since research is changing dramatically, i.e. becoming more multidisciplinary, more collaborative, more global, and more dependent on the capabilities offered through advanced networks and large data storage; there are new opportunities and challenges for information professionals within higher education. Actively engaging in strengthening partnerships with foreign colleagues and with the researchers within our own institutions is an important way to maintain relevance and be beneficial to the research endeavours of our institutions.

The evolving democratic and technological environment provides a window of opportunity for the universities in Africa to re-engineer themselves and reclaim their lost glory. But for universities to optimise the benefits they can accrue using technologies, a number of interventions are needed. Universities need to develop research strategies that will define resource needs; determine quality assurance measures; elaborate on ethical issues online; define peer review processes, collaboration and partnerships with industry and government; and define mechanisms for the commercialisation of research products, mentorship and complaint resolutions.

Scholars should be encouraged to self archive pre-prints and post-prints of their papers in open access archives or institutional repositories to help address the paucity of research materials that face African universities. Institutional Inkanyiso, Jnl Hum \& Soc Sci 2009, I(I) 
repositories can make significant contributions to the visibility and international standing of universities and research organisations in the realm of scholarly communication. Libraries have a critical role to play in digital scholarship. O'Brien (2005) observes that libraries have traditionally been central to the research endeavour by managing and preserving scholarly resources, now increasingly in digitised form, and making these resources accessible to the researcher, often through collaboration and partnerships with other libraries. Libraries have know-how not only in managing, providing access to, and preserving scholarly resources, but also in forming federations and collaborations to share published scholarly work. Moreover, libraries are responsible for developing mechanisms that perfect tools and procedures for enhancing easy access to e-information and e-content, such as portals, gateways, and hypertext links to resources.

\section{References}

Ahemba, T. (2006). 'Decay Dims Africa's Once-Proud Universities'. Reuters, I5 November 2006. Ibadan: Nigeria.

Blair, R.D. D. (199I). An Assessment of Progress and the Potential for Financial Diversification and Income Generation at Selected African Universities. A Report to the World Bank. Harare: Blair Management Services and SPECISS College.

Blair, R and Jordan, J. (1994). Staff Loss and Retention at Selected African Universities: A Synthesis Report. AFTHR Technical Note 18. Washington D. C.

Butcher, (2003). Technological Infrastructure and Use of ICT in Education in Africa: An Overview ADAE, 99

Buchhorn, M. (2004). Research Data Meets the Real World. [Online]. Available at: http://www.aarnet.edu.au/engineering/ middleware/archive/middle/2004/forum/Buchhorn.pps [Accessed I5 September 2008]

Commission for Africa. (2005). Our Common Interest. Report of the Commission for Africa, II March 2005. London.

Council on Higher Education, South Africa. (2000). Developing African Higher Education, Pretoria

Halsey, A.H. (1992). The Decline of Donnish Dominion Oxford, UK: Oxford, University Press.

Institute of Higher Education (2006), Academic Ranking of World Universities. Shanghai Jaio Tong University, China

InternetLab (2008). Top African Universities on the Web. [Online]. Available at: http://www.socialcapitalgateway.org/engrankingafrica.html [Accessed I5 September 2008].

Kenya Times (2006). Kenya Loses 20 Doctors Monthly. Kenya Times, 15 February 2006. [Online]. Available at: http:// www.timesnews.co.ke/I5feb06/mainnews.html [Accessed 16 February 2006].

Lippincott, J.K (2005). Net Generation Students and Libraries. [Online]. Available at: http://www.educause.edu/ educatingthenetgen [Accessed I5 September 2008].

MacGregor, K. (2005). Unity Urged for African Revival. Times Higher Education Supplement, 4 March 2005. London

Maina, S.N. (1989). "Provision of Education through Cost-sharing." Annex 5 (pp. 109-I I3) in J.E.O. Odada and L.O. Odhiambo (Eds.), Report of the Proceeding of the Workshop on Cost-sharing in Kenya: Naivasha 29 March - 2 April 1989. Nairobi: UNICEF, Kenya Country Office, Ministry of Planning and National Development, and Kenyan Economic Association.

Mamdani, M. (2006). Keynote Address to the 16th Conference of Commonwealth Education Ministers: Access to quality education: For the Good of All. Cape Town.

Manyika, S. and Szanton, D.L (200I). PhD Programs in African Universities: Current Status and future Prospects- A Report to the Rockefeller Foundation. Berkley: University of California, Berkley.

O'Brien, L (2005). E-Research: An Imperative for Strengthening Institutional Partnerships. EDUCAUSE Review, 40(6), 64-77.

Oketch M. (2000). Costing and Financing Higher Education for Development in Sub-Saharan Africa: Kenya's Case." International Education Journal-ej, 4(3), I-10.

Onyancha, O.B. (2008). Self-archiving by LIS Schools in South Africa: Practices, Challenges and Opportunities. Paper Presented at 2nd Annual Knowledge Archives \& Records Management Conference, 7 May 2008 at the University of south Africa.

O'Really, T. (2005). Web 2.0: Compact Definition. [Online]. Available at: http://radar.oreilly.com/archives/2005/l0/ web_20_compact_definition.html [Accessed 23 September 2007].

Pienaar, H. (2008). Development and Implementation of an E-Information Strategy for an Academic Library. Paper presented at Libraries and Information management Forum 2008, 21-22 August, 2008, Sandton, Johannesburg, South Africa

Pienaar, H. and van Daventer, M. (2007). Investigating the Need for a Virtual Research Environment (VRE) for Malaria Research in the South African context. [Online]. Available at: $h t t p: / / w w w . a c g t . c o . z a / s a m i / i n d e x . h t m l$ [Accessed I4 September 2008].

Republic of Kenya. (1993). Economic Survey 1993. Central Bureau of Statistics, Office of the Vice President, and Ministry of Planning and National Development. Nairobi: Government Printer

Sawyerr, A. (2006). Renewal of the African University. Invitation to a Discussion on the Development of African Universities, 20 May 2006. Accra: Association of African Universities.

Siringi, S. (2005). Why Universities Missed the Mark. Daily Nation, 14 October 2005

Siringi, S. and Kago, T. (2007). Universities to be Expanded to Admit More Students. Daily Nation, June 29, 2006.

Slaughter S. (1998). National Higher Education Policies in a Global Economy. In Universities and Globalization ed. Currie, J. and Newson, J. London: Sage Publications

Sutherland -Addy, E. (1993). Revolt and Renewal: Reflections on the Creation of a System of Tertiary Education in Ghana. AFTHR Technical Note No 10.

The Standard (2006). Kenyan Varsities Score Poorly in Global Ranking. The Standard I 4 February 2006.

Woodhall, M. (199I). Student Loans in Higher Education: English-speaking Africa. Educational Forum Series No. 3. Paris: International Institute for Educational Planning (UNESCO

Youngman, F. (2007). Opening Speech- Digital Scholarship Conference Held on 12-13 December 2007, at the University of Botswana Library Auditorium. 